\title{
Ureteritis quística en paciente candidata a trasplante renal
}

\author{
E. Argüelles Salido, J. Rodríguez Corchero, Mª A. López García *, Mํㅗ. Pérez Espejo, \\ P. Campoy Martínez, J.Ma Pena Outeiriño
}

Servicio de Urología. *Servicio de Anatomía Patológica. Hospital Universitario Virgen del Rocío. Sevilla.

Actas Urol Esp 2005; 29 (2) 226-229

\section{RESUMEN}

URETERITIS QUÍSTICA EN PACIENTE CANDIDATA A TRASPLANTE RENAL

La ureteritis quística es una patología muy infrecuente, sin que hasta el momento se haya establecido su patogénesis exacta. Se presenta con sintomatología inespecífica, pero sin embargo los hallazgos radiológicos son bastante orientativos.

No hay un tratamiento específico para estos pacientes, siendo el trasplante renal el paso final para los que desarrollen insuficiencia renal crónica terminal (IRCT).

Presentamos un caso de ureteritis crónica diagnosticado durante el estudio pretrasplante de una paciente con IRCT.

Palabras Clave: Pieloureteritis. Ureteritis quística. Trasplante renal. Enfermedades ureterales.

\section{ABSTRACT}

\section{CYSTIC URETERITIS IN A KIDNEY TRASPLANTATION CANDIDATE}

Cystic ureteritis is a very uncommon pathology, whose pathogenesis is not well established. It is usually asociated with chronic infectious factors. It presents unspecific symptoms but characteristic radiologic findings.

There is not an especific treatment for this disease. Kidney trasplant is the final pathway for patients with chronic renal failure.

We report a case of cystic ureteritis diagnosed during pre-trasplant study.

Keywords: Pyeloureteritis. Cystic ureteritis. Kidney trasplant. Ureteral diseases.

$\mathrm{L}^{\mathrm{a}}$ a presencia de quistes de localización submucosa en algún nivel del urotelio recibe el nombre de pieloureteritis, ureteritis o cistitis quística según la zona afectada, que suele ser el tercio superior ureteral, siendo rara la localización vesical.

La pieloureteritis quística (PQ) es una patología de escasa incidencia, que se ha descrito principalmente en adultos de todas las edades, pudiendo afectar también a niños. Su incidencia es similar en ambos sexos, aunque para algunos autores predomina ligeramente en el femenino ${ }^{1}$.

$\mathrm{Su}$ tratamiento es conservador en la gran mayoría de casos. Cuando la afectación es bilate- ral, con macroquistes e IRCT, está indicada en ocasiones la nefrectomía bilateral y el trasplante renal (TR). Esto es excepcional ${ }^{2}$, por lo que presentamos el caso que hemos tenido ocasión de diagnosticar y tratar.

\section{CASO CLÍNICO}

Presentamos el caso de una mujer de 62 años con antecedentes personales de hipertensión arterial en tratamiento desde tres años antes, histerectomía por miomatosis uterina, nefrolitiasis coraliforme bilateral diagnosticada treinta años antes, habiéndosele realizado pielolitectomía izquierda en aquella fecha. IRCT en hemo- 
diálisis atribuida a nefritis túbulo-intersticial crónica secundaria a litiasis renal y a pielonefritis crónica. Pionefrosis derecha que precisó nefrostomia percutánea, evolucionando satisfactoriamente. Posteriormente se realizó nefrectomía derecha, informada como hidronefrosis con litiasis piélica e intensa pielonefritis abscesificada. Leve ureteritis crónica inespecífica.

Una vez que la paciente se recuperó de la última intervención quirúrgica, fue citada para su estudio en consulta pre-trasplante, donde en la cistografía se objetivó una vejiga normal, que vaciaba con mínimo residuo, pero con reflujo vesicoureteral derecho grado I, lo que permitía la detección de múltiples defectos de replección en uréter pélvico, compatibles con ureteritis quística (Fig. 1). Cultivo, baciloscopia y citología de orina negativos.

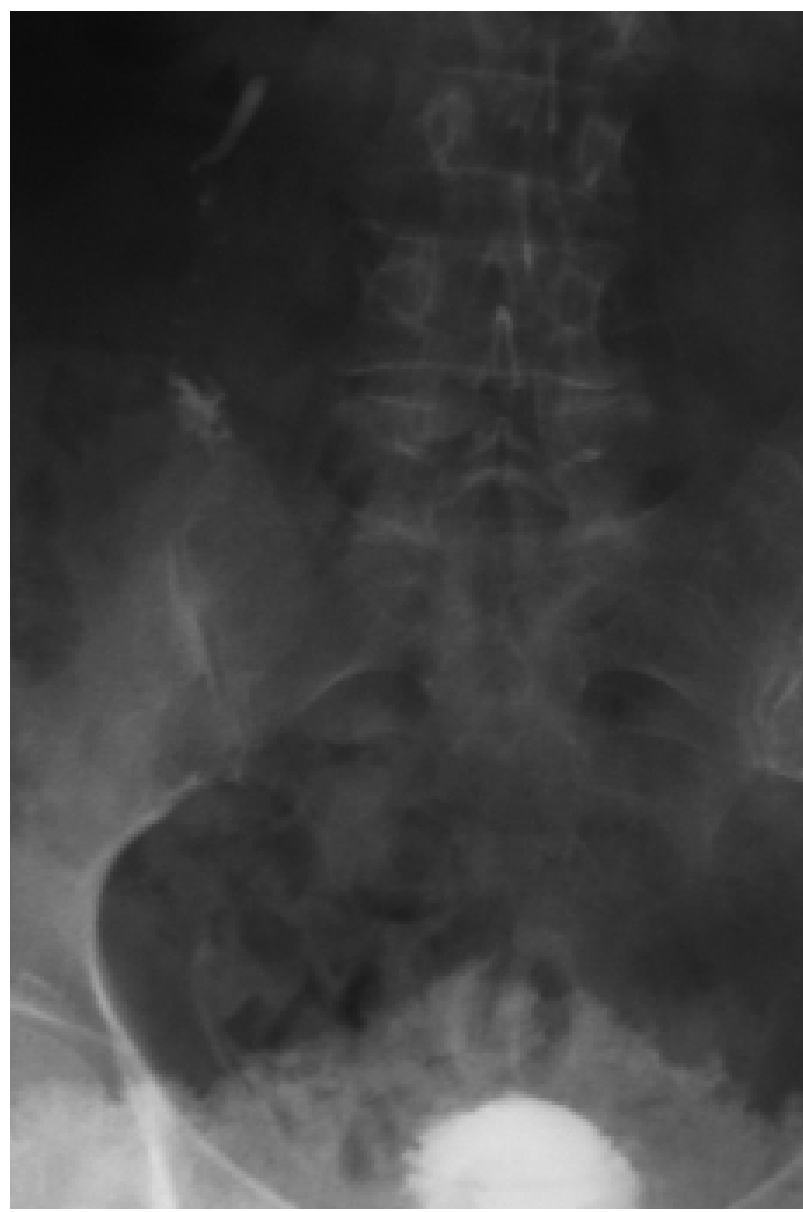

Figura 1. Cistografia en la que se observa un reflujo vesicoureteral derecho grado I, que posibilita la visualización de defectos de replección ureterales múltiples, sugestivos de ureteritis quistica.
Tras la realización del diagnóstico se planteó la extirpación del uréter derecho en el momento del TR, con el objetivo de hacer una confirmación histológica del proceso. De esta forma en Abril de 2001 realizamos TR heterotópico en fosa ilíaca derecha. Previamente y durante la misma intervención se realizó ureterectomía derecha, encontrándose una luz ureteral con abundantes quistes de contenido claro, cuya biopsia intraoperatoria fue informada de ureteritis quística (Fig. 2).

El postoperatorio ha cursado sin incidencias, estando actualmente asintomática y con creatinina estable en torno a $1,3 \mathrm{mg} / \mathrm{dL}$.

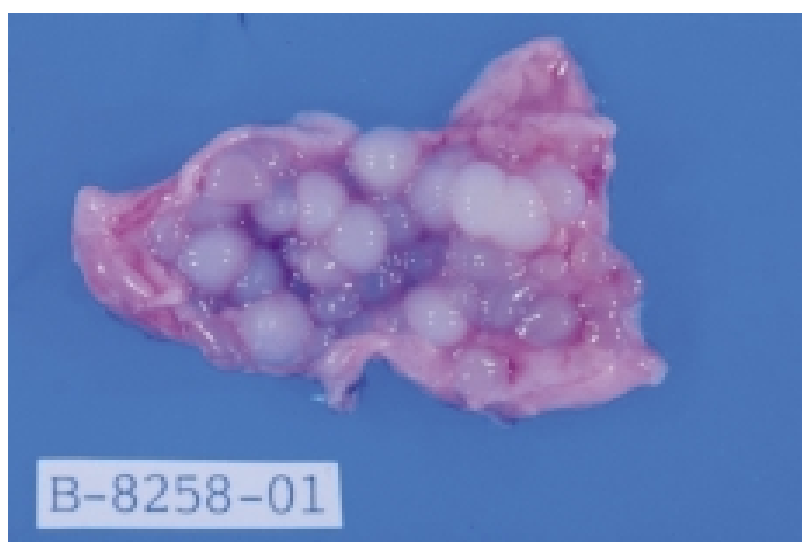

Figura 2: pieza de ureterectomía en la que observamos la luz ureteral ocupada por formaciones quisticas de contenido claro, en número abundante, caracteristica de la pieloureteritis quistica.

\section{DISCUSIÓN}

Morgagni en 1716 describió por primera vez la PQ. Jacob en 1929 observó sus características imágenes radiológicas y Kindall realizó algo después su descripción de un modo extenso. Chevassu en 1936 describió el primer caso de bilateralidad. Pérez Castro la presentó en España por primera vez en $1946^{3}$, y hasta la fecha se han publicado en literatura española 75 casos, siendo las series mayores las de Puigvert y cols. ${ }^{4}$ en 1971 (11 casos), Ricós Torrent y cols en 1981 (10

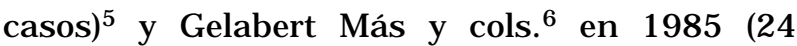
casos) $^{2}$. En literatura extranjera destaca la revisión de 34 casos de Menéndez y cols 7 .

Es una afección adquirida del adulto, aunque en algún caso la descripción de casos infantiles como antes mencionamos ha puesto en duda esta afirmación. Otro punto en discusión es su frecuencia de bilateralidad, pudiendo encontrar- 
se autores que sostienen que ésta es lo más frecuente $^{8,9}$, y otros que sostienen lo contrario ${ }^{1 .}$ En la revisión de Menéndez y cols el 79\% de los casos la presentaba de manera unilateral. En nuestro caso sólo se presentaba en uréter derecho.

Su patogenia es aún un tema discutido, aunque teoría más afectada es la de Lubarsch de 1983 que sostiene que la presencia de estímulos irritativos sostenidos del urotelio llevaría a una metaplasia submucosa y originaria nidos de von Brünn. Estos posteriormente sufrirían degeneración quística por licuefacción central.

Son muchos los factores que en algún momento han sido relacionados con la PQ, como hipo o avitaminosis A, la bilharziasis y las alteraciones inmunes con aumento de IgA. Hoy en día se ha desechado estas relaciones. Sí hay acuerdo en la necesidad de la presencia de un estímulo inflamatorio, describiéndose que un $30 \%$ y un $50 \%$ de los casos han presentado previamente pielonefritis o litiasis del tracto urinario respectivamente $^{8}$, como ha sucedido en el caso que presentamos.

Su presentación clínica es muy variable, superponiéndose muchas veces a la provocada por los factores inflamatorios o infecciosos que intervienen en la patogenia de la enfermedad. Así podemos encontrar infección urinaria (82\%), hematuria (52\%), dolores renoureterales vagos, cólico nefrítico y litiasis (53\%) y dolor abdominal inespecífico. A estos síntomas hay que añadir los derivados de un hipertensión mantenida o de insuficiencia renal crónica, en los que puede desembocar esta patología cuando los casos son evolucionados. Es posible además que la enfermedad no presente clínica alguna, sino que se diagnostique de manera incidental, durante el estudio de alguna otra patología. Efectivamente en nuestro caso el diagnóstico se hizo de manera incidental durante la preparación de la paciente para el TR, habiendo hasta entonces presentado únicamente sintomatología compatible con pielonefritis de repetición y la piohidronefrosis referida, debido a la litiasis coraliforme.

La urografía o la pielografía ascendente son las técnicas de imagen con las que más frecuentemente se llega a la sospecha diagnóstica de esta enfermedad. En ambas podemos observar defec- tos de replección numerosos, de contornos lisos bien definidos y redondeados, dando un aspecto festoneado o "apolillado"10. Otros hallazgos posibles pero menos frecuentes son la presencia de hidronefrosis como resultado de la obstrucción del sistema afecto $^{11}$, o anulación funcional renal 12. La cistografía, gracias a la presencia de reflujo vesicoureteral, hizo posible el diagnóstico en nuestro caso, pudiendo encontrarse dos casos en la literatura con similar forma de diagnóstico ${ }^{7}$.

El mejor método diagnóstico es el endoscópico, visualizándose en la zona urotelial afecta formaciones quísticas en número diverso, redondeadas, de pared fina translúcida, permitiendo observar un contenido quístico en su mayoría de veces claro, aunque en ocasiones puede ser algo más hemorrágico. Este contenido se suele componer de agua, proteínas, restos celulares y algunos pigmentos ${ }^{13}$.

Anatomopatológicamente estas formaciones son de localización submucosa y sus paredes están formadas por epitelio estratificado con un algún infiltrado linfoplasmocitario.

El diagnóstico diferencial debe realizarse con todas las patologías ureterales capaces de originar imágenes de defecto de repleción, principalmente carcinoma transicional y ureteritis tuberculosa. Para realizar esta distinción serán muy útiles la citología y la baciloscopia, negativas en caso de PQ. Otros procesos a descartar son litiasis radiotrasparentes, coágulos, gas en la vía excretora.

En la mayoría de las ocasiones la actitud conservadora, con tratamiento de los procesos infecciosos o litiásicos desencadenantes, junto a un correcto seguimiento, suelen ser suficientes en el manejo de la enfermedad. Sólo en casos en que los quistes provoquen obstrucción del sistema excretor, hipertensión o insuficiencia renal estaría indicado tratamiento quirúrgico, con nefroureterectomía. En ocasiones se ha empleado el cateterismo ureteral con inyecciones de nitrato de plata para romper los quistes, pero actualmente se piensa que la posibilidad de yatrogenia es mayor que el beneficio que este procedimiento puede proporcionar.

Su evolución es benigna, estando en discusión si el tamaño o el número de quistes presentes modifican ésta. Algunos autores sin embargo, basándose en su similitud con la cistitis glandular, 
ponen en duda que su evolución sea invariablemente benigna. Por ello proponen un seguimiento mediante análisis de orina, citología y cultivo semestrales, y urografía anual ${ }^{8}$.

\section{REFERENCIAS}

1. Mariño del Real J, Sevilla Zabaleta M, Cabello Padial J et al: Ureteritis quística: importancia de la infección-inflamación crónica como factor etiológico. Aportación de un caso clínico. Actas Urol Esp 2000;24(6):496-498.

2. Romero Pérez P, Amat Cecilia M, González Devesa M: Pieloureteritis quística. Revisión de la literatura, periodo 1946-1994 y presentación de un nuevo caso. Actas Urol Esp 1995;19(3):252-257.

3. Perez Castro E: Ureteritis quística. Arch Esp Urol 1946;3(1): 43-61.

4. Puigvert A, Elizalde A, Roselló M: Ureteritis quística. A propósito de 11 casos. An Fund Puigvert 1971;1(3):141-158.

5. Ricos Torrent JV, Solsona Narbón E, Colomer González, et al.: Pieloureteritis quística. Presentación de diez casos. Arch Esp Urol 1981;34 (3):183-192.

6. Gelabert Mas A, Guzman Hernandez A, Aguado I: veinticinco nuevos casos de quistosis urotelial. Arch Esp Urol 1985; 38(1):14-18.

7. Menéndez V, Sala X, Álvarez-Vijande R, et al. Cystic Pieloureteritis. Review of 34 cases. radiologic aspects and differential diagnosis. Urology 1997;50(1):31-37.
8. Pereira Arias J, Escobal Tamayo V, Maraña Fernández MT, et al: Pieloureteritis quística. Un diagnóstico a tener en cuenta. Arch Esp de Urol 1995;48(2):194-196.

9. Duffin TK, Regan JB, Hernández-Graulau JM: Ureteritis cystica with 17-year follow up. J Urol 1994;151:142-143.

10. Luque Arana JI, Diez Diez JA, García Tapia E: Ureteritis quística. Presentación de un caso y revisión de la literatura nacional más reciente. Arch Esp de Urol 1990;43(6): 668-671.

11. Navas Pastor J, Morga Egea JP, García Ligero J, et al: Pieloureteritis quística e infección. Formas de presentación y revisión de la literatura. Arch Esp de Urol 2000; 53(1):15-20.

12. Oleza Simo J, Ponce Socorro M, Roselló Barbara M, et al: Ureteritis quística. Presentación de dos casos. Actas Urol Esp 1979;3: 279.

13. Castillo Jimeno JM, Santiago González de Garibay A, Ruiz Rubio JL, et al: Pieloureteritis quística: nuestra actitud. Arch Esp de Urol 1992;45(4):363-364.

Enrique Argüelles Salido

Milano Plomizo $\mathrm{n}^{\circ} 4$, portal $4,1^{\mathrm{a}} \mathrm{B}$

41020 Sevilla.

earguelles@telefonica.net

(Trabajo recibido el 23 abril de 2004) 